\title{
Relationship of obesity with respiratory symptoms and decreased functional capacity in adults without established COPD
}

\author{
* Moshe Zutler ${ }^{\mathrm{a}, \mathrm{b}}$, Jonathan P Singer ${ }^{\mathrm{a}, \mathrm{b}}$, Theodore A Omachi ${ }^{\mathrm{a}, \mathrm{b}}$, Mark Eisnerc, \\ Carlos Iribarren ${ }^{\mathrm{d}}$, Patricia Katz ${ }^{\mathrm{e}}$, Paul D Blanc $\mathrm{c}^{\mathrm{a}, \mathrm{b}, \mathrm{f}}$
}

a Department of Pulmonary, Critical Care, Allergy and Sleep Medicine, University of California, San Francisco, California, USA
b Department of Cardiovascular Research Institute, University of California, San Francisco, California
c Product Development Inflammation and Respiratory, Genentech Inc, South San Francisco, California, USA
${ }^{\text {d }}$ Kaiser Division of Research, Kaiser Permanente Medical Care Program, Oakland, California, USA
e Department of Medicine, University of California, San Francisco, California, USA
${ }^{\dagger}$ Department of Occupational and Environmental Medicine, University of California, San Francisco, California, USA

Originally received 25th August 2011; resubmitted 7th December 2011; revised 11th January 2012; accepted 23rd January 2012; online 28th March 2012

\begin{abstract}
Background: Obesity contributes to respiratory symptoms and exercise limitation, but the relationships between obesity, airflow obstruction (AO), respiratory symptoms and functional limitation are complex.

Aims: To determine the relationship of obesity with airflow obstruction (AO) and respiratory symptoms in adults without a previous diagnosis of chronic obstructive pulmonary disease (COPD).

Methods: We analysed data for potential referents recruited to be healthy controls for an ongoing study of COPD. The potential referents had no prior diagnosis of COPD or healthcare utilisation attributed to COPD in the 12 months prior to recruitment. Subjects completed a structured interview and a clinical assessment including body mass index, spirometry, six-minute walk test (SMWT), and the Short Performance Physical Battery (SPPB). Multiple regression analyses were used to test the associations of obesity (body mass index $\geq 30 \mathrm{~kg} / \mathrm{m}^{2}$ ) and smoking with $\mathrm{AO}$ (forced expiratory volume in $1 \mathrm{~s} /$ forced vital capacity ratio $<0.7$ ). We also tested the association of obesity with respiratory symptoms and impaired functional capacity (SPPB, SMWT), adjusting for AO.

Results: Of 371 subjects (aged 40-65 years), 69 (19\%) had AO. In multivariate analysis, smoking was positively associated with AO (per 10 pack-years, $\mathrm{OR} 1.24 ; 95 \% \mathrm{Cl} 1.04$ to 1.49$)$ while obesity was negatively associated with $\mathrm{AO}(\mathrm{OR} 0.54 ; 95 \% \mathrm{Cl} 0.30$ to 0.98$)$. Obesity was associated with increased odds of reporting dyspnoea on exertion (OR 3.6; $95 \% \mathrm{Cl} 2.0$ to 6.4$)$, productive cough (OR $2.5 ; 95 \% \mathrm{Cl}$ 1.1 to 6.0$)$, and with decrements in SMWT distance $(67 \pm 9 \mathrm{~m} ; 95 \% \mathrm{Cl} 50$ to $84 \mathrm{~m})$ and SPPB score (OR $1.9 ; 95 \% \mathrm{Cl} 1.1$ to 3.5$)$. None of these outcomes was associated with AO.

Conclusions: Although $\mathrm{AO}$ and obesity are both common among adults without an established COPD diagnosis, obesity (but not AO) is linked to a higher risk of reporting dyspnoea on exertion, productive cough, and poorer functional capacity.

(C) 2012 Primary Care Respiratory Society UK. All rights reserved.

M Zutler et al. Prim Care Respir J 2012; 21(2): 194-201

http://dx.doi.org/10.4104/pcrj.2012.00028
\end{abstract}

Keyw ords airflow obstruction, COPD, dyspnoea, functional status, health status, obesity

See linked editorial by Franssen on pg 131

The full version of this paper, with online appendix,

is available online at www.thepcrj.org

\section{Introduction}

Based on epidemiological studies, the prevalence of spirometrydefined chronic obstructive pulmonary disease (COPD) ranges from $10 \%$ to $15 \%$ and, among cigarette smokers, it increases to

\footnotetext{
* Corresponding author: Dr M oshe Zutler, Department of Pulmonary, Critical Care, Allergy and Sleep M edicine, University of California, 505 Parnassus Ave, M 1097, San Francisco, California, CA 94143, USA. Tel: +1 (415) 353-2961 Fax: +1 (415) 353-2568 E-mail: moshe.zutler@ucsf.edu
} 
$25 \% \cdot \cdot^{1-3}$ Furthermore, it has been estimated that approximately two-thirds of individuals with COPD remain undiagnosed. ${ }^{1}$ However, the clinical relevance of such airflow limitation remains a matter of debate. Many individuals with airflow obstruction (AO) identified through population-based testing are asymptomatic, while others have respiratory complaints consistent with COPD., 1,2, Factors other than smoking are also likely to contribute to both spirometry-defined obstruction and the presence of respiratory symptoms. Among these, obesity may be particularly relevant.

Obesity has long been recognised as a major contributor to respiratory symptoms and exercise limitation, independent of $A O .^{5}$ The potential inter-relationships between obesity, $A O$, and respiratory symptoms or functional limitations are complex. Increased body mass index (BMI) is clearly linked to a greater risk of asthma; ${ }^{6-9}$ in contrast, lower BMI appears to be linked to smoking-related emphysema. ${ }^{6,10}$ While increased BMI has been shown to have a negative association with COPD in most studies, ${ }^{5,6,10-12}$ at least one investigation has reported an association in the opposite direction. ${ }^{13}$ Obesity is known to cause a restrictive ventilatory deficit, but the combination of obesity and COPD has been linked to a mixed obstructive and restrictive ventilatory defect. ${ }^{14}$ The net result therefore makes it difficult to differentiate between the contributions from obesity and $A O$ in symptomatic individuals. ${ }^{15}$ It is therefore not surprising that the primary care provider faces the dilemma of how to evaluate and treat abnormal respiratory symptoms in obese patients, especially in the presence of concomitant $A O .^{16}$

Previous studies of obesity and $A O$ have included spirometry but have not brought objective exercise capacity assessments to bear in addressing this difficult question., ${ }^{2,-6,6,8,14}$ As part of a larger study of COPD, we used data from a pool of referents recruited expressly because they lacked a known clinical diagnosis of COPD. Some of the otherwise eligible referents, however, were found to have $A O$ on spirometry. Because all potential referent subjects - both with and without $A O$ completed structured symptom questionnaires and physical assessments, we were able to use these data to examine the inter-relationships among lung function, obesity, respiratory symptoms, and exercise limitations in a population without a COPD diagnosis.

\section{Methods}

\section{Overview}

The Function, Living, Outcomes and Work (FLOW) study of COPD is an ongoing prospective cohort study of adults recruited from the Kaiser Permanente Medical Care Program (KPMCP), an integrated healthcare organisation in northern California. ${ }^{17-20}$ The KPMCP population has previously been shown to be well representative of the regional population. ${ }^{21}$ At the time of the original cohort formation, a referent group of subjects without COPD was concurrently recruited. Baseline recruitment and assessment have been described in detail previously. ${ }^{17}$ In brief,

\section{Figure 1. Referent recruitment and exclusions}

2021 patients age 40-65 without COPD ICD-9-CM diagnosis codes $(491,492,496)$ matched to cases by gender, age, and race
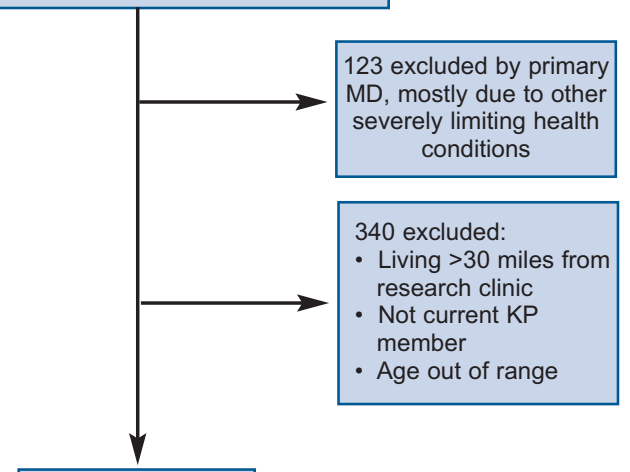

1558 eligible

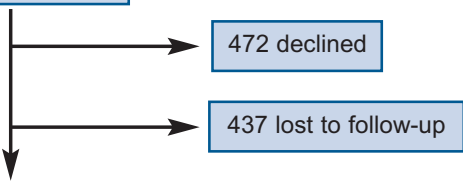

649 interviewed (42\% of eligible)

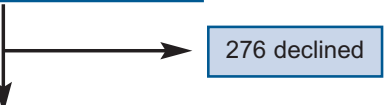

eted clinic visit

(57\% of interviewed)

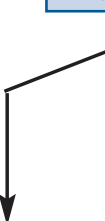

302 without

airflow

bstruction

$\left[\mathrm{FEV}_{1} / \mathrm{FVC}\right.$

$\geq 0.70]$

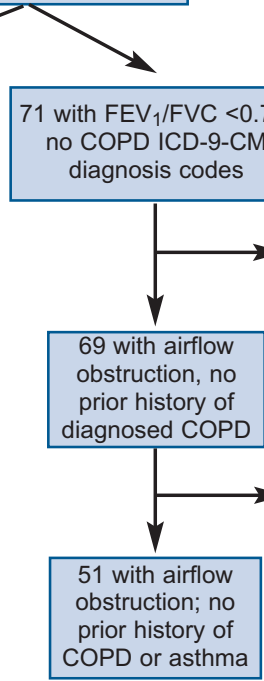

$\mathrm{COPD}=$ chronic obstructive pulmonary disease, $\mathrm{FEV} 1=$ forced expiratory volume in $1 \mathrm{~s}, \mathrm{FVC}=$ forced vital capacity, $\mathrm{KP}=$ Kaiser Permanente

subjects aged 40-65 were screened from the KPMCP for the presence of both healthcare utilisation and medication dispensation consistent with COPD. The referent group comprised subjects matched for age, sex, and race-ethnicity whose medical records lacked the presence of any ICD-9 diagnosis codes for COPD (chronic bronchitis [491], emphysema [492], or COPD [496]) for any healthcare utilisation within 


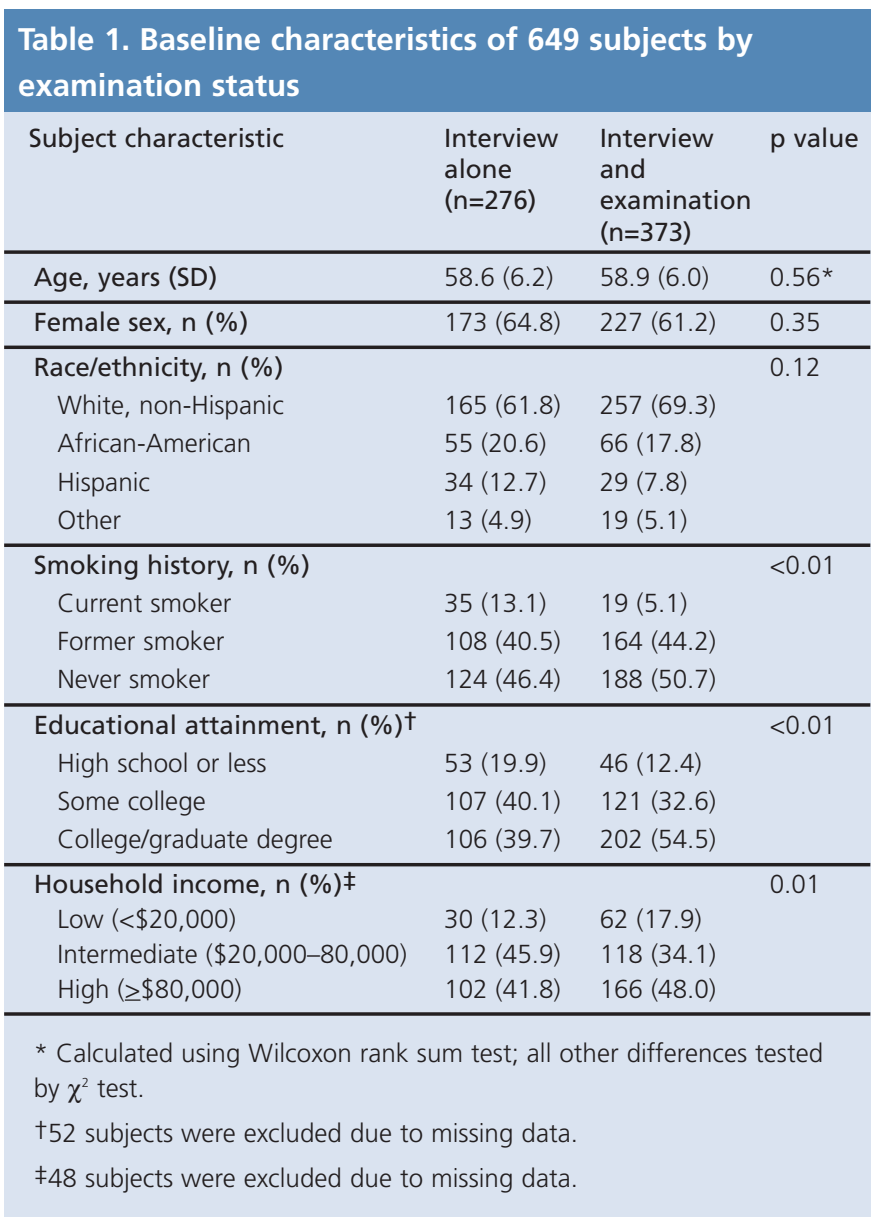

KPMCP in the 12 months prior to recruitment. Utilisation based on ICD-9 diagnosis codes for other respiratory complaints, including asthma, was not an exclusion criterion. All FLOW baseline participants, both those with COPD and referents, completed structured telephone interviews and underwent a research clinic visit that included spirometric measurement and other physical assessments.

Subject recruitment

Referent recruitment in the FLOW study is shown in Figure 1. We originally identified 2,021 potential referents of whom 1,558 were eligible for inclusion in the study; $649(42 \%$ of the eligible subject pool) went on to complete structured interviews. Of these 649 subjects, $373(57 \%)$ completed the research clinic visit. The differences between those who did and did not complete research clinic visits are shown in Table 1. There were no statistical differences in age, sex, or race-ethnicity by research clinic visit follow-up status. Those with examination data were more likely to be never smokers, have higher educational attainment, and to be in the extremes of household income.

Interview data

Subjects completed structured telephone interviews prior to their research clinic visit. Data obtained during the interviews included sociodemographics, medical history, health status and symptoms, direct tobacco exposure, and secondhand smoke exposure. Specifically, in terms of health status, we questioned subjects regarding detailed respiratory symptoms including dyspnoea with exertion and productive cough. The structured interview also included the Medical Outcomes Survey Short Form (SF-12) instrument. ${ }^{22}$ We assessed global health status using the single SF-12 item, "In general, would you say your health is excellent, very good, good, fair or poor?" For our analyses we dichotomised responses to this global self-rated health item as excellent/very good or good/fair/poor. A number of approaches have analysed five-level scale global self-rated health items, including comparing the two uppermost levels with the lower three response options, as we did here. ${ }^{23}$ Other approaches include dichotomising at a lower cut-off point of fair to poor health ${ }^{24,25}$ or studying multiple levels as separate indicator variables relative to either single extreme. ${ }^{26}$ We chose our cut-off point (excellent/very good compared with good/fair/poor) to allow sufficient observations in each analytical cell for stability in model estimation.

\section{Assessment of pulmonary function}

To assess respiratory impairment we performed spirometry according to American Thoracic Society (ATS) guidelines. ${ }^{27,28}$ We used the EasyOne ${ }^{T M}$ Frontline spirometer (ndd Medical Technologies, Chelmsford, MA, USA) which meets ATS criteria. To calculate percentage predicted values, including the lower limit of normal (LLN) for the forced expiratory volume in 1s to forced vital capacity ( $\mathrm{FEV}_{1} / \mathrm{FVC}$ ) ratio, we used predictive equations derived from NHANES III. ${ }^{29}$ We did not administer bronchodilators. In addition to spirometry, we measured height and weight to calculate BMI. We defined obesity as BMI $\geq 30 \mathrm{~kg} / \mathrm{m}^{2}$.

All 373 subjects who completed the research visit performed spirometry. Of these, $71(19 \% ; 95 \% \mathrm{Cl} 15 \%$ to $23 \%)$ were found to have $\mathrm{AO}$, defined by an $\mathrm{FEV}_{1} / \mathrm{FVC}$ ratio of $<0.7$. These subjects had been excluded from all previous referent group analyses in the principal FLOW analyses (Figure 1). We defined these 71 subjects as having AO without known COPD. Two subjects were excluded because they reported a physician's diagnosis of COPD in their structured interviews despite the fact that this was not reflected in the KPM CP electronic databases.

Of the 69 subjects with AO, 44 subjects $(64 \%)$ had an $\mathrm{FEV}_{1} / \mathrm{FVC}$ ratio below the LLN; two of the 302 in the non-AO group as defined by the fixed ratio were nonetheless also below the LLN, yielding a total of 46 out of 371 subjects $(12.4 \%)$ with LLN-defined obstruction.

Because the referent recruitment strategy did allow for asthma, we reviewed the KPMCP electronic databases within 12 months of the initial recruitment date to identify those with healthcare utilisation for asthma and dispensing of bronchodilator or inhaled corticosteroid medication. There were 18 such subjects among the 69 remaining referents with $\mathrm{AO}$. This information was used to perform sensitivity analyses (see Statistical analysis below). Excluding these, the remaining 51 persons among a reduced total of 353 yielded a prevalence 
estimate for undiagnosed $\mathrm{AO}$ of $14 \%(95 \% \mathrm{Cl} 11 \%$ to $19 \%)$. Direct assessment of functional limitations

Submaximal exercise performance was measured using the sixminute walk test (SMWT), consistent with the ATS protoco ${ }^{30-32}$ and lower extremity function was measured using the Short Physical Performance Battery (SPPB). ${ }^{33-35}$ This battery includes three performance measures, each scored from 1-4 points (maximum 12 points). The standing balance test asks subjects to maintain their feet in a side-by-side, semi-tandem stand, or tandem stand for 10s. A test of walking speed requires subjects to walk $4 \mathrm{~m}$ at normal pace; participants are assigned a score of 1-4 based on the quartile of length of time needed to complete the test. The chair stand test, a measure of lower extremity extensor muscle strength, measures the time required for the subject to stand up and sit down from a chair five times with arms folded across the chest; scores of 1-4 are assigned based on the quartile of time taken to complete the task. The summary performance combining all three measures has excellent interobserver reliability as well as predictive validity. ${ }^{33-35}$ In this analysis, subjects were dichotomised into two groups: those in the lowest quintile (SPPB score $<11$ ) who were defined as having poor lower extremity functioning compared with all others (SPPB score $\geq 11$ ). Statistical analysis

Statistical analysis was performed using STATA software Version 11.2 (StataCorp LP, College Station, TX, USA). Differences in descriptive characteristics by research clinic status and by presence or absence of AO were tested by $\chi^{2}$ or Wilcoxon rank sum test. Multivariable logistic regression analysis was used to study smoking and obesity in relation to the presence of $A O$, controlling for age, sex, and race-ethnicity. Logistic regression was also used to analyse the relationship between $A O$ and obesity as independent predictors of respiratory symptoms, selfreported health status, and performance on the SPPB adjusted for age, sex, and race-ethnicity. We also tested the association of an AO-obesity interaction term included in the same models. We used multivariable linear regression to test $A O$ and obesity as independent predictors of SMWT distance, controlling for the same covariates (SM WT distance measurements were missing for two subjects, both without obstruction). Median percentage predicted forced expiratory flow over $25-75 \%$ of expired volume $\left(\mathrm{FEF}_{25-75)}\right.$ between the obese and non-obese groups was compared using the Wilcoxon rank sum test. For key outcomes, additional sensitivity analyses were performed redefining obstruction based on LLN and, separately, excluding those subjects with asthma in the $\mathrm{FEV}_{1} / \mathrm{FVC}$ ratio $<0.7$ defined obstruction group. Hosmer-Lemeshow tests were performed to confirm the goodness of fit in our logistic regression models ( $p>0.15$ for all models tested).

\section{Results}

\section{Characteristics of subjects with and without AO}

Compared with others in the referent cohort, the 69 subjects with $\mathrm{AO}$ were more likely to be non-Hispanic white, older, and
Table 2. Baseline characteristics of 371 referent subjects: airflow obstruction compared with all others

\begin{tabular}{|c|c|c|c|}
\hline \multirow[b]{2}{*}{ Subject characteristic } & \multicolumn{2}{|c|}{ Airflow obstruction } & \multirow{2}{*}{$\begin{array}{l}\text { All others } \\
\text { No } \\
\text { obstruction } \\
(n=302)\end{array}$} \\
\hline & $\begin{array}{l}\text { Asthmatics } \\
\text { excluded } \\
\text { ( } n=51)\end{array}$ & $\begin{array}{l}\text { Any } \\
\text { obstruction } \\
(n=69)\end{array}$ & \\
\hline Age, mean, years $(S D) *$ & $60.7(5.1)$ & $60.5(4.9)$ & $58.5(6.1)$ \\
\hline Female sex, $\mathrm{n}(\%)$ & $29(56.9)$ & $42(60.9)$ & $185(61.2)$ \\
\hline \multicolumn{4}{|l|}{ Race/ethnicity terms, $\mathrm{n}(\%)^{*}$} \\
\hline White, non-Hispanic & $42(82.4)$ & $57(82.6)$ & $200(66.2)$ \\
\hline Other & $9(17.6)$ & $12(17.4)$ & $102(33.8)$ \\
\hline \multicolumn{4}{|l|}{ Educational attainment, $\mathrm{n}(\%)^{\dagger}$} \\
\hline High school or less & $4(7.8)$ & $6(8.7)$ & $40(13.3)$ \\
\hline Some college & $17(33.3)$ & $26(37.7)$ & 95 (31.5) \\
\hline College/graduate degree & $30(5$ & $37(53.6)$ & $165(54.6)$ \\
\hline \multicolumn{4}{|l|}{ Household income, $\mathrm{n}(\%)^{\dagger}$} \\
\hline Low $(<\$ 20,000)$ & $2(3.9)$ & $2(2.9)$ & $9(3.0)$ \\
\hline Intermediate $(\$ 20,000-80,000)$ & $22(43.1)$ & $32(46.4)$ & $137(45.4)$ \\
\hline High $(\geq \$ 80,000)$ & $26(51.0)$ & $33(47.8)$ & $133(44.0)$ \\
\hline \multicolumn{4}{|l|}{ Smoking exposure, $\mathrm{n}(\%)$} \\
\hline \multicolumn{4}{|l|}{ Smoking status* } \\
\hline Current smoker & $6(1$ & $7(10.1)$ & $12(4.0)$ \\
\hline Former smoker & $25(4$ & $32(46.4)$ & $132(43.7)$ \\
\hline Never smoker & $20(39.2)$ & $30(43.5)$ & $158(52.3)$ \\
\hline $\begin{array}{l}\text { Pack-years for ever smokers, } \\
\text { median (interquartile range)* }\end{array}$ & $27(12,42)$ & $27(12,41)$ & $19(9.5,29.5)$ \\
\hline Secondhand smoke exposure†* & $21(41.2)$ & $28(40.5)$ & $119(39.4)$ \\
\hline $\mathrm{BMI} \geq 30, \mathrm{n}(\%)^{*}$ & $9(17.6)$ & $19(27.5)$ & $128(42.4)$ \\
\hline \multicolumn{4}{|c|}{$\begin{array}{l}\text { * } p<0.05, \text { No airflow obstruction compared to obstruction (asthmatics } \\
\text { excluded or any obstruction). Age and pack-years comparison by Wilcoxon } \\
\text { rank sum; all other differences tested by } \chi^{2} \text { test. }\end{array}$} \\
\hline \multicolumn{4}{|c|}{$\begin{array}{l}\text { Two subjects were excluded from this analysis due to missing data for } \\
\text { education and } 24 \text { due to missing data for income; } 20 \text { active smokers } \\
\text { excluded from secondhand smoke exposure analysis. }\end{array}$} \\
\hline
\end{tabular}

less likely to be obese (Table 2). There were 147 subjects with obesity (40\%; $95 \% \mathrm{Cl} 35 \%$ to $45 \%$ ); among the non-obese subjects only one had a $\mathrm{BMI} \leq 18.5 \mathrm{~kg} / \mathrm{m}^{2}$. Subjects with $\mathrm{AO}$ also had a higher prevalence of ever smoking, although this difference was not statistically significant ( $57 \%$ vs. $48 \%$; $\mathrm{p}=0.08$ ). Among ever smokers, those with $A O$ reported significantly higher lifetime cumulative smoking ( 27 vs. 19 packyears; $p=0.02$ ). There were no significant differences between those with and without $\mathrm{AO}$ in sex, educational attainment, secondhand smoke exposure, or annual household income.

By definition, those with $\mathrm{AO}$ had abnormal lung function with a median $\mathrm{FEV}_{1} / \mathrm{FVC}$ ratio of 0.67 (see Appendix Table 1 available online at www.thepcrj.org). Their median $\mathrm{FEV}_{1}$ was $83 \%$ of predicted, with a lower 10th percentile range value of $62 \%$ predicted. The median $\mathrm{FEF}_{25-75}$ was $56 \%$ predicted, with a lower 10th percentile range value of $33 \%$ predicted. The median percentage predicted $\mathrm{FEF}_{25-75}$ (25-75th percentile) was $90 \%$ (68-113\%) among non-obese subjects and 93\% (66-125\%) among obese subjects; there was no statistically significant 


\begin{tabular}{|c|c|c|}
\hline & $\begin{array}{l}\text { Unadjusted } \\
\text { OR }(95 \% \mathrm{Cl})\end{array}$ & $\begin{array}{l}\text { Adjusted* } \\
\text { OR }(95 \% \mathrm{Cl})\end{array}$ \\
\hline \multicolumn{3}{|l|}{ All subjects included $(n=371)$} \\
\hline $\begin{array}{l}\text { Obesity }\left(\mathrm{BMI} \geq 30 \mathrm{~kg} / \mathrm{m}^{2}\right) \\
\text { Cumulative smoking, per }\end{array}$ & 0.52 (0.29 to 0.92$)$ & 0.54 (0.30 to 0.98$)$ \\
\hline 10 pack-years & 1.25 (1.05 to 1.49$)$ & $1.24(1.04$ to 1.49$)$ \\
\hline \multicolumn{3}{|c|}{$\begin{array}{l}\text { Excluding subjects with obstruction and any healthcare utilisation } \\
\text { for asthma }(n=353)\end{array}$} \\
\hline $\begin{array}{l}\text { Obesity (BMI } \geq 30 \mathrm{~kg} / \mathrm{m}^{2} \text { ) } \\
\text { Cumulative smoking, per }\end{array}$ & $0.29(0.14$ to 0.62$)$ & 0.29 (0.13 to 0.63$)$ \\
\hline 10 pack-years & $1.33(1.10$ to 1.62$)$ & $1.34(1.10$ to 1.64$)$ \\
\hline
\end{tabular}

*OR adjusted for age, sex, race-ethnicity.

$\mathrm{BMI}=$ body mass index, $\mathrm{FEV}_{1}=$ forced expiratory volume in $1 \mathrm{~s}$,

$\mathrm{FVC}=$ forced vital capacity.

difference in $\mathrm{FEF}_{25-75}$ percentage predicted by obesity status $(p=0.36)$. The mean FVC percentage predicted was lower in obese subjects than in non-obese subjects $(91.3 \pm 1.4 \%$ vs. 96.2 $\pm 1.0 \% ; p<0.01$ ).

After adjusting for age, sex, and race-ethnicity, each 10 packyear increase in cumulative smoking was associated with a $25 \%$ increased odds of $A O(O R 1.24 ; 95 \% \mathrm{Cl} 1.04$ to 1.49 ; Table 3). Notably, in the same multivariate model, those who were obese were half as likely to have $A O(O R \quad 0.54 ; 95 \% \mathrm{Cl} 0.30$ to 0.98 ). Using the $\amalg N$-based definition, obesity remained negatively associated with $\mathrm{AO}$, but less strongly and not significantly so (OR $0.68 ; 95 \% \mathrm{Cl} 0.35$ to $1.3 ; p=0.26$ ); the association of smoking with $\mathrm{AO}$ was similar to the previous analysis (per 10 pack-years, OR 1.37; $p<0.01$ ). Re-estimating these associations excluding the 18 subjects with asthma from the AO group yielded similar albeit strengthened - results (per 10 pack-years, OR 1.34; 95\%
$\mathrm{Cl} 1.1$ to 1.6 ; obesity, OR $0.29 ; 95 \% \mathrm{Cl} 0.13$ to 0.63$)$ - see Appendix Table 2 available online at www.thepcrj.org.

Symptoms and functional outcomes

In multiple logistic regression analyses controlling for age, sex, race-ethnicity, and obesity, AO was not associated with productive cough, dyspnoea on exertion, self-reported good/fair/poor health, or lower SPPB score (Table 4; top portion). In the same multivariate model, however, obesity was associated with more than a two-fold increased risk of productive cough (OR 2.5; $95 \% \mathrm{Cl} 1.1$ to 6.0 ) and more than a three-fold increased risk of dyspnoea on exertion (OR 3.6; $95 \% \mathrm{Cl} 2.0$ to 6.4). In addition, obesity was associated with a markedly higher likelihood of self-reported good/fair/poor health (OR 4.5; $95 \% \mathrm{CI}$ 2.8 to 7.3) and a higher likelihood of poor lower extremity functioning (lowest quintile SPPB score OR 1.9; $95 \% \mathrm{Cl} 1.03$ to 3.3). No significant interaction between $A O$ and obesity was observed for any of the outcomes for which both factors manifested increased point estimates of risk (cough, dyspnoea, and good/fair/poor health) ( $p>0.4$ in all cases). In an alternative analysis adjusting for obesity, there was no statistically significant association between LLN-defined $\mathrm{AO}$ and dyspnoea on exertion (OR $1.4 ; 95 \% \mathrm{Cl} 0.6$ to $3.1 ; p=0.4$ ).

Excluding those in the AO group who had asthma $(n=18$; bottom portion of Table 4) gave similar results. There was no discernible association between $A O$ and productive cough, dyspnoea on exertion, self-reported good/fair/poor health, or lowest quintile SPPB score. Obesity remained statistically associated with dyspnoea on exertion (OR 3.3; $95 \% \mathrm{Cl} 1.8$ to 6.1), self-reported good/fair/poor health $(\mathrm{OR} 4.3 ; 95 \% \mathrm{Cl} 2.6$ to 7.1), and poor lower extremity functioning (OR 1.9; $95 \% \mathrm{Cl} 1.1$ to 3.5), while the relationship with productive cough was no longer statistically significant $(\mathrm{OR} 2.3,95 \% \mathrm{Cl} 0.9$ to 5.8; $p=0.09$ ).

\begin{tabular}{|c|c|c|c|c|c|}
\hline \multirow[t]{2}{*}{ Outcome characteristic } & \multirow[t]{2}{*}{$\mathrm{n}(\%)$} & \multicolumn{2}{|c|}{ Risk associated with obstruction } & \multicolumn{2}{|c|}{ Risk associated with obesity } \\
\hline & & $\begin{array}{l}\text { Unadjusted } \\
\text { OR }(95 \% \mathrm{Cl}) \\
\end{array}$ & $\begin{array}{l}\text { Adjusted* } \\
\text { OR }(95 \% \mathrm{Cl}) \\
\end{array}$ & $\begin{array}{l}\text { Unadjusted } \\
\text { OR }(95 \% \mathrm{Cl})\end{array}$ & $\begin{array}{l}\text { Adjusted } \dagger \\
\text { OR }(95 \% \mathrm{Cl}) \\
\end{array}$ \\
\hline \multicolumn{6}{|c|}{ All subjects included $(n=371)$} \\
\hline Productive cough & $24(7 \%)$ & 1.9 (0.8 to 4.8$)$ & $2.1(0.8$ to 5.5$)$ & $2.3(0.97$ to 5.2$)$ & $2.5(1.1$ to 6.0$)$ \\
\hline Dyspnoea on exertion & $63(17 \%)$ & $1.2(0.6$ to 2.3$)$ & 1.4 (0.7 to 2.8$)$ & 3.6 (2.0 to 6.3$)$ & $3.6(2.0$ to 6.4$)$ \\
\hline Good/fair/poor health & $117(32 \%)$ & $0.8(0.4$ to 1.4$)$ & $1.1(0.6$ to 2.0$)$ & 4.8 (3.0 to 7.6$)$ & $4.5(2.8$ to 7.3$)$ \\
\hline SPPB $<11$ & $59(16 \%)$ & $1.0(0.5$ to 2.1$)$ & $1.0(0.5$ to 2.1$)$ & 1.9 (1.1 to 3.3$)$ & 1.9 (1.03 to 3.3$)$ \\
\hline \multicolumn{6}{|c|}{ Excluding 18 subjects with obstruction and any healthcare utilisation for asthma $(n=353)$} \\
\hline Productive cough & $20(6 \%)$ & $1.0(0.3$ to 3.7$)$ & $1.3(0.4$ to 5.0$)$ & $2.0(0.8$ to 5.0$)$ & $2.3(0.9$ to 5.8$)$ \\
\hline Dyspnoea on exertion & $54(15 \%)$ & $0.4(0.2$ to 1.2$)$ & $0.6(0.2$ to 1.7$)$ & $3.6(1.9$ to 6.5$)$ & $3.3(1.8$ to 6.1$)$ \\
\hline Good/fair/poor health & $107(30 \%)$ & $0.4(0.2$ to 0.95$)$ & $0.7(0.3$ to 1.5$)$ & $4.8(2.9$ to 7.7$)$ & $4.3(2.6$ to 7.1$)$ \\
\hline SPPB $<11$ & $56(16 \%)$ & $1.0(0.4$ to 2.2$)$ & $1.0(0.4$ to 2.3$)$ & $1.9(1.1$ to 3.3$)$ & 1.9 (1.1 to 3.5$)$ \\
\hline
\end{tabular}


The mean SM WT distance for the entire group $(n=369)$ was $522 \pm 90 \mathrm{~m}$. In multiple linear regression analysis, adjusting for age and sex, the presence of obesity was associated with a $67 \pm$ $9 \mathrm{~m}$ decrement in SM WT distance $(95 \% \mathrm{Cl}-84$ to $-50 ; \mathrm{p}<0.001)$. In contrast, $\mathrm{AO}$ was associated with a non-statistically significant increase of $5 \pm 12 \mathrm{~m}(95 \% \mathrm{Cl}-19$ to $+29 ; p>0.7)$.

\section{Discussion}

\section{Main findings}

In this study of adults enrolled in an integrated healthcare organisation, airflow obstruction (AO) among those without a known COPD diagnosis was not associated with a discernible increased likelihood of subjective respiratory symptoms, poorer self-reported health status, or decrements in functioning including the SPPB and SM WT.

Interpretation of findings in relation to previouslypublished work

Notably, obesity was associated with a lower likelihood of AO as defined by an $\mathrm{FEV}_{1} / \mathrm{FVC}$ ratio $<0.7$, an effect that has been seen in earlier cross-sectional studies of previously undiagnosed $A O .^{5,10-12}$ This is in contrast to those with established COPD, where a positive association between COPD and increased BMI has been reported, ${ }^{13}$ an effect that was previously reported by our group among those with diagnosed COPD in the study arm of the FLOW cohort not included in this analysis. ${ }^{36}$ The mechanism(s) of any protective effect of obesity on the presence of non-clinically diagnosed AO remain to be elucidated. Clearly, there appears to be a difference between the relationship of obesity in non-clinically diagnosed $A O$ and clinically diagnosed COPD. Once COPD has been clinically diagnosed, there is a subset of patients who evolve to manifest lower BMI and have worse outcomes overall. ${ }^{37-40}$ Persons with concomitant clinically diagnosed COPD and obesity may therefore reflect a survival bias leading to a higher proportion of patients with established COPD who are obese. Nonetheless, extrapolating from this sample to persons with non-clinically diagnosed $\mathrm{AO}$ without clinical disease would be overly speculative at this time.

Obesity, but not AO, was associated with productive cough, dyspnoea on exertion, and self-assessed poorer health status. In addition, SPPB was impaired and SM WT distance was reduced in the presence of obesity. These associations are consistent with the existing literature documenting a convincing link between obesity and poorer functional status. ${ }^{41-43}$ Furthermore, the lack of association between decreased lung function and either respiratory symptoms or subjective quality of life decrements seen in our study is also well established in the existing literature. Many previous studies have shown a relatively weak association between decrements in lung function per se and decreased healthrelated qualify of life or decreased functional status. ${ }^{44-47}$ Our study re-confirms this observation, suggesting that obesity is more strongly associated with the increased respiratory symptoms and decreased functional capacity that were seen in our cohort.

In our cohort, obesity was less strongly and not significantly associated with $A O$ as defined by the LLN of the $\mathrm{FEV}_{1} / \mathrm{FVC}$ ratio, and we observed no significant obesityassociated difference in the median $\mathrm{FEF}_{25-75}$. Redefining AO based on the LLN reduced the prevalence of abnormality in this cohort (12.4\% vs. $19 \%)$ ). Although our power to detect significant associations was compromised by the restricted numbers with $A O$ thus defined, the point estimate of the obesity risk for $A O$ was similar and in the direction of lower OR (0.7 vs. 0.5), as was the weak association of $A O$ with dyspnoea on exertion (1.4 vs. 1.2).

Taken together, our results suggest that, among those without previously diagnosed COPD, airflow obstruction per se does not contribute to respiratory symptoms, functional capacity, or self-rated global health status in a statistically significant or clinically meaningful way. Rather, we found that obesity in this group plays a larger and more meaningful explanatory role. It is therefore possible that interventions intended to improve dyspnoea may achieve greater impact by reducing obesity rather than by overly focusing on labelling AO detected through screening as COPD and treating this with medications.

Strengths and limitations of this study

A particular strength of this analysis is the systematic characterisation of symptoms and the objective measures of physiological functioning (pulmonary function, SM WT, and SPPB) in a sample recruited from a large integrated healthcare organisation generalisable to other primary care settings. In addition, for our analysis we dichotomised BMI (obese vs. non-obese) rather than treating this as a linear variable. Even though this may result in some loss of statistical power, obesity so defined is the accepted and more clinically relevant measure. Moreover, including non-smokers as well as smokers in our study group is more relevant to the mixed general primary care population. By the same token, symptoms were not used as a screening criterion for entry into the study; limiting spirometric screening only to symptomatic populations is likely to introduce selection bias, both in regard to $\mathrm{AO}$ and obesity.

Limitations of this analysis include its relatively narrow adult age range, modest sample size, geographical concentration in northern California and the absence of postbronchodilator measurements of lung function. Subjects were intentionally chosen within a specific age range (40-65 years) because the focus of the parent FLOW study was disability among persons of working age; this may limit generalisability to older populations where $\mathrm{AO}$ may be more prevalent and may have differing relationships with obesity. Some of the associations we observed did not achieve statistical significance, but might have done so with larger study numbers. Nonetheless, other weak associations, such as the 
change in SMWT linked to AO, are in the opposite direction to an adverse effect and do not suggest a larger study size alone would have led to an adverse effect being observed. Selection of referents may have contributed a source of bias in our study; overall we were able to recruit 649 subjects from 1,558 of those eligible ( $42 \%$ ), with 373 subjects participating (57\% of the total recruited). Comparing individuals who participated in our study to those who did not, however, revealed a higher incidence of current or former smoking in the non-participation group. Had these non-participants been included in our study, this would probably have increased the incidence of $A O$, given the observed relationship between smoking and $\mathrm{AO}$.

We studied subjects recruited from northern California, and this geographical limitation should be kept in view when generalising to other regions. We did not administer bronchodilators prior to lung function assessment, which may have falsely labelled some subjects with AO who may have had reversible obstruction; this is particularly relevant because a subset of the subjects with $\mathrm{AO}$ were likely to have asthma. We addressed this issue by carrying out sensitivity analyses for all key models excluding such subjects. These demonstrated similar associations. We recognise the possibility that persons with AO who did not have a prior diagnosis of asthma (and thus were not excluded from sensitivity analyses based on that diagnosis) nonetheless had that condition, which could influence the results seen in our study. Our study primarily focused on obstruction defined by an $\mathrm{FEV}_{1} / \mathrm{FVC}$ ratio $<0.7$. The LLN approach, which we tested secondarily, may be more precise, but the fixed ratio approach is far more widely used and better understood in general primary care settings. ${ }^{48,49}$ Finally, in the setting of concomitant obesity and AO, obesity may lower the FVC which can appear to 'normalise' the $\mathrm{FEV}_{1} / \mathrm{FVC}$ ratio in the presence of a decreased $\mathrm{FEV}_{1}$. This effect, to the extent operative, would tend to misclassify those with $\mathrm{AO}$ and concomitant obesity into the non-AO group, making obesity appear to be less frequent in $\mathrm{AO}$. Of note, FVC as percentage predicted was indeed lower among obese compared with non-obese subjects. If misclassified AO accounted for the relationship between obesity and respiratory symptoms in our cohort, however, we would have expected a strong association between increased BMI and abnormal FEF 25-75, which was not the case.

\section{Conclusions}

Although airflow obstruction $(A O)$ is relatively common in adults without an established COPD diagnosis, and even though this impairment is related to cumulative smoking history, it may not be associated with respiratory symptoms or functional status. In contrast, obesity is negatively associated with the presence of $\mathrm{AO}$ and is strongly linked both to symptoms and functional impairment, even taking $A O$ into account. Strategies to manage respiratory symptoms and functional impairment among those with airflow limitation should consider the contribution of obesity to such abnormalities.

\section{Handling editor Gopal Netuveli \\ Statistical review Gopal Netuveli}

Conflicts of interest The authors declare that they have no conflicts of interest in relation to this article.

Contributorship M Z and PB had access to the data, and were responsible for conception and design of the study, as well as interpretation, analysis and writing. JS contributed to the analysis, interpretation and writing. TO, ME, CI and PK contributed to the revision of the manuscript.

Funding This research was supported by the Flight Attendant's M edical Research Institute (FAM RI Bland Lane Center for Excellence in Secondhand Smoke) and the University of California Tobacco-Related Diseases Research Program (17RT-0101), and the National Heart, Lung, and Blood Institute at the National Institutes of Health (5T32HL7185-34).

\section{References}

1. Mannino DM, Gagnon RC, Petty TL, Lydick E. Obstructive lung disease and low lung function in adults in the United States: data from the National Health and Nutrition Examination Survey, 1988-1994. Arch Intern Med 2000;160(11):1683-9. http://dx.doi.org/10.1001/archinte.160.11.1683

2. Yawn B, Mannino D, Littlejohn T, et al. Prevalence of COPD among symptomatic patients in a primary care setting. Curr Med Res Opin 2009;25(11):2671-7.

3. Murtagh E, Heaney L, Gingles J, et al. Prevalence of obstructive lung disease in a general population sample: the NICECOPD study. Eur J Epidemiol 2005;20(5):44353. http://dx.doi.org/10.1007/s10654-005-1248-8

4. Coultas DB, Mapel D, Gagnon R, Lydick E. The health impact of undiagnosed airflow obstruction in a national sample of United States adults. Am J Respir Crit Care Med 2001;164(3):372-7

5. Sin DD, Jones RL, Man SFP. Obesity is a risk factor for dyspnea but not for airflow obstruction. Arch Intern Med 2002;162(13):1477-81.

http://dx.doi.org/ 10.1001/archinte.162.13.1477

6. Guerra S, Sherrill DL, Bobadilla A, M artinez FD, Barbee RA. The relation of body mass index to asthma, chronic bronchitis, and emphysema. Chest 2002;122(4):1256-63. http://dx.doi.org/10.1378/chest.122.4.1256

7. Camargo CA, Weiss ST, Zhang S, Willett WC, Speizer FE. Prospective study of body mass index, weight change, and risk of adult-onset asthma in women. Arch Intern Med 1999;159(21):2582-8. http://dx.doi.org/10.1001/archinte.159.21.2582

8. Nystad W, Meyer HE, Nafstad P, Tverdal A, Engeland A. Body mass index in relation to adult asthma among 135,000 Norwegian men and women. Am J Epidemio 2004;160(10):969-76. http://dx.doi.org/10.1093/aje/kwh303

9. Schachter LM, Salome CM, Peat JK, Woolcock AJ. Obesity is a risk for asthma and wheeze but not airway hyperresponsiveness. Thorax 2001;56(1):4-8 http://dx.doi.org/10.1136/thorax.56.1.4

10. Harik-Khan RI, Fleg JL, Wise RA. Body mass index and the risk of COPD. Chest 2002;121(2):370-6. http://dx.doi.org/10.1378/chest.121.2.370

11. Nemery B, M oavero NE, Brasseur L, St?nescu DC. Smoking, lung function, and body weight. $\mathrm{Br}$ Med J (Clin Res Ed) 1983;286(6361):249-51. http://dx.doi.org/10.1136/bmj.286.6361.249

12. Lam K-BH, Jordan RE, Jiang CQ, et al. Airflow obstruction and metabolic syndrome: the Guangzhou Biobank Cohort Study. Eur Respir J 2010;35(2):317-23. http://dx.doi.org/10.1183/09031936.00024709

13. Leone $N$, Courbon D, Thomas F, et al. Lung function impairment and metabolic syndrome: the critical role of abdominal obesity. Am J Respir Crit Care Med 2009;179(6):509-16. http://dx.doi.org/10.1164/rccm.200807-11950C

14. Ora J, Laveneziana P, Ofir D, et al. Combined effects of obesity and chronic obstructive pulmonary disease on dyspnea and exercise tolerance. Am J Respir Crit Care Med 2009;180(10):964-71.

15. van den Bemt L, Smeele IJM, Kolkman M, et al. Low body mass index, airflow obstruction, and dyspnoea in a primary care COPD patient population. Prim Care Respir J 2010;19(2):118-23. http://dx.doi.org/10.4104/pcrj.2009.00073

16. Walters JA, Walters EH, Nelson $M$, et al. Factors associated with misdiagnosis of COPD in primary care. Prim Care Respir J 2011;20(4):396-402. http://dx.doi.org/10.4104/pcrj.2011.00039 
17. Eisner MD, Blanc PD, Yelin EH, et al. COPD as a systemic disease: impact on physical functional limitations. Am J Med 2008;121(9):789-96. http://dx.doi.org/10.1016/j.amjmed.2008.04.030

18. Singer J, Yelin EH, Katz PP, et al. Respiratory and skeletal muscle strength in chronic obstructive pulmonary disease: impact on exercise capacity and lower extremity function. J Cardiopulm Rehabil Prev 2011;31(2):111-19.

19. Eisner MD, Iribarren C, Blanc PD, et al. Development of disability in chronic obstructive pulmonary disease: beyond lung function. Thorax 2011;66(2):108-14. http://dx.doi.org/10.1136/thx.2010.137661

20. Eisner MD, Iribarren $C$, Yelin $E H$, et al. Pulmonary function and the risk of functional limitation in chronic obstructive pulmonary disease. Am J Epidemiol 2008;167(9):1090-101. http://dx.doi.org/10.1093/aje/kwn025

21. Krieger $\mathrm{N}$. Overcoming the absence of socioeconomic data in medical records: validation and application of a census-based methodology. Am J Public Health 1992;82(5):703-10. http://dx.doi.org/10.2105/AJPH.82.5.703

22. Ware J, Kosinski M, Keller SD. A 12-Item Short-Form Health Survey: construction of scales and preliminary tests of reliability and validity. Med Care 1996;34(3):220-33. http://dx.doi.org/10.1097/00005650-199603000-00003

23. Shega JW, Ersek M, Herr K, et al. The multidimensional experience of noncancer pain: does cognitive status matter? Pain Med 2010;11(11):1680-7. http://dx.doi.org/10.1111/j.1526-4637.2010.00987.x

24. Nguyen HQ, Donesky-Cuenco D, Carrieri-Kohlman V. Associations between symptoms, functioning, and perceptions of mastery with global self-rated health in patients with COPD: a cross-sectional study. Int J Nurs Stud 2008;45(9):1355-65. http://dx.doi.org/10.1016/j.jpurstu.2007.09.012

25. Butterfield MC, Williams AR, Beebe T, et al. A two-county comparison of the HOUSES index on predicting self-rated health. J Epidemiol Community Health 2011;65(3):2549. http://dx.doi.org/10.1136/jech.2008.084723

26. DeSalvo KB, Fan VS, MCDonell MB, Fihn SD. Predicting mortality and healthcare utilization with a single question. Health Serv Res 2005;40(4):1234-46. http://dx.doi.org/10.1111/j.1475-6773.2005.00404.x

27. Anon. Standardization of Spirometry, 1994 update. American Thoracic Society. Am J Respir Crit Care Med 1995;152(3):1107-36.

28. Anon. Standardization of spirometry--1987 update. Statement of the American Thoracic Society. Am Rev Respir Dis 1987;136(5):1285-98. http://dx.doi.org/10.1164/ajrccm/136.5.1285

29. Hankinson JL, Odencrantz JR, Fedan KB. Spirometric reference values from a sample of the general U.S. population. Am J Respir Crit Care Med 1999;159(1):179-87.

30. Guyatt GH, Sullivan MJ, Thompson PJ, et al. The 6-minute walk: a new measure of exercise capacity in patients with chronic heart failure. Can Med Assoc J 1985;132(8):919-23.

31. Sciurba F, Criner GJ, Lee SM, et al. Six-minute walk distance in chronic obstructive pulmonary disease: reproducibility and effect of walking course layout and length. Am J Respir Crit Care Med 2003;167(11):1522-7. http://dx.doi.org/10.1164/rccm.200203-1660C

32. Anon. ATS statement: guidelines for the six-minute walk test. Am J Respir Crit Care Med 2002;166(1):111-17.

33. Guralnik JM, Simonsick EM, Ferrucci L, et al. A short physical performance battery assessing lower extremity function: association with self-reported disability and prediction of mortality and nursing home admission. J Gerontol 1994;49(2):M 85-94.

34. Guralnik JM, Ferrucci L, Simonsick EM, Salive ME, Wallace RB. Lower-extremity function in persons over the age of 70 years as a predictor of subsequent disability. N Engl J Med 1995;332(9):556-61.

http://dx.doi.org/10.1056/ NEJM 199503023320902

35. Guralnik JM, Ferrucci L, Pieper CF, et al. Lower extremity function and subsequent disability: consistency across studies, predictive models, and value of gait speed alone compared with the short physical performance battery. J Gerontol A Biol Sci M ed Sci 2000;55(4):M 221-31. http://dx.doi.org/10.1093/gerona/55.4.M 221

36. Eisner MD, Blanc PD, Sidney $S$, et al. Body composition and functional limitation in COPD. Respir Res 2007;8:7. http://dx.doi.org/10.1186/1465-9921-8-7

37. Ran P-xin, Wang C, Yao W-zhen, et al. [A study on the correlation of body mass index with chronic obstructive pulmonary disease and quality of life]. Zhonghua Jie $\mathrm{He} \mathrm{He}$ Hu Xi Za Zhi 2007;30(1):18-22.

38. Landbo C, Prescott E, Lange P, Vestbo J, Almdal TP. Prognostic value of nutritional status in chronic obstructive pulmonary disease. Am J Respir Crit Care Med 1999;160(6):1856-61.

39. Gray-Donald K, Gibbons L, Shapiro S, Macklem P, Martin J. Nutritional status and mortality in chronic obstructive pulmonary disease. Am J Respir Crit Care Med 1996;153(3):961-6.

40. Schols AM, Slangen J, Volovics L, Wouters EF. Weight loss is a reversible factor in the prognosis of chronic obstructive pulmonary disease. Am J Respir Crit Care Med 1998;157(6 Pt 1):1791-7.

41. Imai K, Gregg EW, Chen YJ, et al. The association of BMI with functional status and self-rated health in US adults. Obesity (Silver Spring) 2008;16(2):402-08. http://dx.doi.org/10.1038/oby.2007.70

42. Jensen GL, Hsiao PY. Obesity in older adults: relationship to functional limitation. Curr Opin Clin Nutr Metab Care 2010;13(1):46-51. http://dx.doi.org/ 10.1097/M C0.0b013e32833309cf

43. Villareal DT, Chode S, Parimi N, et al. Weight loss, exercise, or both and physical function in obese older adults. N Engl J Med 2011;364(13):1218-29. http://dx.doi.org/10.1056/NEJM oa1008234

44. Jones PW. Health status measurement in chronic obstructive pulmonary disease. Thorax 2001;56(11):880-7. http://dx.doi.org/10.1136/thorax.56.11.880

45. Hajiro T, Nishimura $K$, Tsukino $M$, et al. Comparison of discriminative properties among disease-specific questionnaires for measuring health-related quality of life in patients with chronic obstructive pulmonary disease. Am J Respir Crit Care Med 1998:157(3 Pt 1):785-90.

46. Wijkstra PJ, TenVergert EM, van der Mark TW, et al. Relation of lung function, maximal inspiratory pressure, dyspnoea, and quality of life with exercise capacity in patients with chronic obstructive pulmonary disease. Thorax 1994;49(5):468-72. http://dx.doi.org/10.1136/thx.49.5.468

47. Jones PW, Quirk FH, Baveystock CM, Littlejohns P. A self-complete measure of health status for chronic airflow limitation. The St. George's Respiratory Questionnaire. Am Rev Respir Dis 1992;145(6):1321-7.

48. Ferguson GT. Office spirometry for lung health assessment in adults: a consensus statement from the National Lung Health Education Program. Chest 2000;117(4):1146-61. http://dx.doi.org/10.1378/chest.117.4.1146

49. Rabe KF, Hurd S, Anzueto A, et al. Global strategy for the diagnosis, management, and prevention of chronic obstructive pulmonary disease: GOLD Executive Summary. Am J Respir Crit Care Med 2007;176(6):532-55. http://dx.doi.org/ 10.1164/rccm.200703-456SO

\section{Available online at http://w ww.thepcrj.org}




\section{Appendix 1}

Table 1. Characteristics of 69 subjects with airflow

obstruction

\begin{tabular}{|c|c|}
\hline Measure & Median (10th - 90th percentile) \\
\hline $\mathrm{FEV}_{1} / \mathrm{FVC}$ ratio & $0.67(0.59,0.69)$ \\
\hline $\mathrm{FEV}_{1}(\mathrm{~L})$ & $2.38(1.62,3.24)$ \\
\hline $\mathrm{FEV}_{1} \%$ predicted & $83.8(61.9,108.2)$ \\
\hline FVC (L) & $3.64(2.57,4.89)$ \\
\hline FVC \% predicted & $95.3(78.0,116.6)$ \\
\hline $\mathrm{FEF}_{25-75}(\mathrm{~L} / \mathrm{s})$ & $1.36(0.73,1.99)$ \\
\hline $\mathrm{FEF}_{25-75} \%$ predicted & $56.2(33.3,73.8)$ \\
\hline Peak flow (L/s) & $6.51(4.53,8.94)$ \\
\hline Peak flow \% predicted & $92.6(70.1,116.2)$ \\
\hline
\end{tabular}

$\mathrm{FEV}_{1}=$ forced expiratory volume in $1 \mathrm{~s}, \mathrm{FVC}=$ forced vital capacity,

FEF25-75=forced expiratory flow over $25-75 \%$ of the expired volume.

Table 2. Characteristics of 51 subjects with airflow

obstruction after excluding subjects with asthma

\begin{tabular}{|c|c|}
\hline Measure & Median (10th - 90th percentile) \\
\hline $\mathrm{FEV}_{1} / \mathrm{FVC}$ ratio & $0.67(0.59,0.69)$ \\
\hline $\mathrm{FEV}_{1}(\mathrm{~L})$ & $2.45(1.87,3.29)$ \\
\hline $\mathrm{FEV}_{1} \%$ predicted & $87.8(70.0,109.0)$ \\
\hline FVC (L) & $3.83(2.81,4.94)$ \\
\hline FVC $\%$ predicted & $96.1(81.5,119.5)$ \\
\hline $\mathrm{FEF}_{25-75}(\mathrm{~L} / \mathrm{s})$ & $1.41(0.94,2.01)$ \\
\hline $\mathrm{FEF}_{25-75} \%$ predicted & $57.4(37.6,73.9)$ \\
\hline Peak Flow (L/s) & $6.73(5.17,9.22)$ \\
\hline
\end{tabular}

